\title{
From an African Oral Tale to an English Picture Book: Rwandan Teachers' Experience with Online Translation of South African Institute of Distance Education's African Storybooks
}

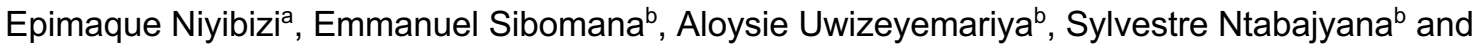 \\ Cyprien Niyomugabo \\ University of Johannesburg; University of Rwanda - College of Education ${ }^{\text {a }}$ \\ University of Rwanda - College of Education ${ }^{b}$
}

\section{Vol 1 No 12019}

ISSN: 2788-6298

DOI: https://doi.org/10.35293/tetfle.v1i1.66

\begin{abstract}
Research findings pertaining to language education and distance education point to the lack of online reading materials written in African languages and reflecting African contexts. Such a shortage is a challenge to literacy skills development in Africa. In Rwanda, although there are some graded readers to support the teaching of reading in Kinyarwanda, there is a shortage of enjoyable storybooks on which children can practice their reading skills. This paper contributes to addressing this challenge by investigating the partnership between the University of Rwanda-College of Education and South African Institute of Distance Education's (Saide) African Storybook Initiative, which provides a website of digital storybooks in Kinyarwanda and other languages for early grade reading. Data were collected from 32 Rwandan teacher educators who participated in a workshop. Participants created online picture storybooks in Kinyarwanda, translated some from other languages and published them on the African Storybook website. The researchers firstly observed their activities during the workshop, then, all participants filled in the questionnaire and ten teachers were interviewed on opportunities offered and challenges encountered during the translation process. The key finding is that teachers' experiences with translation revealed differences in story reading levels between the original Kinyarwanda folktales and English translated versions. They found special features of African agglutinating languages in determining reading levels, and foreignization of translated stories based on cultural clashes. Differences in length between the original and the translated stories were observed, as well as the specificity of English versions in reinforcing more critical thinking than the translated Kinyarwanda versions. The paper recommends teacher educators and translators to bear in mind that adaptation to African languages requires care and a high level of ability to maintain the meaning and moral lesson of the original tale and make it enjoyable for children. Translating and adapting stories from English into agglutinative African languages have implications for early grade reading interventions in African schools since children stories on African storybook website are available in more than 100 African languages.
\end{abstract}

Keywords: African storybook initiative; early years reading; Kinyarwanda folktales; agglutinating language; Saide; University of Rwanda-College of Education.

CONTACT Epimaque Niyibizi @ eniyibizi@yahoo.fr 


\section{Introduction}

Rwanda is among African countries where reading materials in local languages are not enough. Various studies including Williams, de Montfort-Nayimfashe, Ntakirutimana and O'Sullivan (2004); Niyomugabo (2008); Niyibizi (2015a); Niyibizi (2015b); Sibomana (2015) reported that early grade reading abilities in Rwandan schools were revealed to be insufficient. For instance Williams et al. (2004) investigated the reading abilities among 251 grade six primary school learners in Rwanda and found that more than $90 \%$ of the sample were able to read adequately in Kinyarwanda, a language which they were using as a medium of instruction, but only $0.77 \%$ of 251 grade six primary school learners who were tested in five schools in Rwanda were able to read adequately for their studies in English at primary school level. Niyibizi (2015a) also observed that primary school teachers and learners have different levels of proficiency in Kinyarwanda and English.

As a solution to such a shortage of reading materials in African languages and African context, The African Storybook (www.africanstorybook.org) Initiative was established. Hence, this paper falls under the theme of distance teacher education, within the African perspective based on the African Storybook Initiative. While teachers in Rwandan primary schools have many interesting stories for oral storytelling, they need additional knowledge to harness this richness to create storybooks and translate the existing ones from other languages, so that children can have sufficient stories to read by themselves. This paper reports on the participating teachers' experiences in creating and translating picture storybooks, especially African folktales versus English picture storybooks.

\section{Background on African Storybook Initiative and Saide-URCE partnership}

The paper is based on the partnership between the South African Institute of Distance Education (SAIDE) and the University of Rwanda - College of Education (UR-CE), which was initiated in 2017 and introduced the African Storybook initiative, website and storybooks in Rwanda. The African Storybook (ASb) is an initiative of the South African Institute of Distance Education (Saide), a South African Non-Governmental Organization with a footprint across Southern Africa, East and West Africa. African Storybook Initiative is addressing the severe shortage of appropriate books for early 
reading in the languages of Africa, and such a shortage has a great impact on the literacy development of the poorest $80 \%$ of people in African countries. An observation of the African Storybook website on 28th October 2017 revealed that there were over four thousand storybooks in 100 languages, with 842 in English, 129 in French, and 82 in Kinyarwanda. These numbers increase almost on a daily basis.

The African Storybook provides free, digital, openly licensed storybooks, with creation and translation tools for users to publish their own storybooks. On the African Storybook website people are able to create their own picture storybooks in their own languages; to search an expanding library of storybooks created elsewhere in Africa; to choose the stories they like and use them; or to translate and adapt the stories for the language, context or level they need.

The online storybooks can be read on a cell phone, tablet or laptop, or downloaded onto a flash drive and projected as big books on a classroom wall. They can also be printed out as booklets on a home or office printer for use by students or children.

\section{The aim of the study}

The main aim of this study is to investigate the opportunities offered and challenges encountered while participants created and translated stories into Kinyarwanda and English picture storybooks and posted them on the African Storybook website. Specifically, the study seeks to answer the following research questions:

1. What were the teacher educators' experiences in creating, translating and adapting stories into Kinyarwanda and then posting them on the African Storybook platform?

2. What are the opportunities offered and challenges encountered along the process of creating, translating and adapting stories into Kinyarwanda?

\section{Introduction to African knowledge systems: oral tales, oral literature, folktales and picture books}

African oral tales, oral literature, folktales and picture books are explored in this paper and are viewed as traditional and cultural African knowledge systems. The nuances between the four concepts are the following: oral literature is described as the opposite of written literature, but various scholars (Nandwa and Bukenya, 1983; Okpewho, 
1992; Okombo, 1994; Killick and Boffey, 2012; Rossister, 2002) described them from different perspectives. These scholars interchangeably used several terms for the concept of 'oral literature'; for example, Nandwa and Bukenya (1983), Miruka and Sunkuli (1990), Okpewho (1992) and Okombo (1994) suggest terms like orature, traditional literature, folk literature, folktale and folklore. As a nuance between folktale and oral literature, Nandwa and Bukenya (1983, p.1) argued that folktales constitute a subgenre of oral literature, where folktales are "those utterances, whether spoken, recited or sung, whose composition and performance exhibit to an appreciable degree the artistic characteristics of accurate observation, vivid imagination and ingenious expression". As for Miruka and Sunkuli (1990, p.36), a folktale is described as "a popular traditional story handed down orally through generations". One objective of folktales is to preserve social and cultural values and norms in order to perpetuate the society. Folktales are common in many cultures and have existed since the beginning of civilisation; their authors are usually unknown, there are often many versions of one tale, and they are transmitted orally by storytellers (Nandwa \& Bukenya, 1983; Miruka \& Sunkuli, 1990).

The oral tale is also described as one of the genres of oral literature, which is conveyed through the art of storytelling, or a way of educating and teaching children (Pedersen, 1995). Nandwa and Bukenya (1983) described it as those utterances, which are spoken, recited or sung. Similarly, Killick and Boffey (2012) described storytelling as one of the oldest and most powerful forms of communication, where stories are means of gaining new perspectives, exploring moral choices and gaining insight into characters. Such a description supports Rossister's (2002) viewpoint that the major role of storytelling is to deliver lessons and pass history down from one generation to another, relying heavily on mental images. Picture books, which constitute one of the printed forms of literature, come to fill in the gaps by adding visual images. As children are sensitive to pictures even before they start speaking, Rossister (2002) and Killick and Boffey (2012) confirm that they enjoy reading picture books. A picture book is a book combining both texts and illustrations to be more attractive and readable, and this kind of book is normally written for children. The pictures in the book expand the meaning of the text, making it more attractive to children and helping them enjoy reading (Kress and Van Leeuwen, 1996). Such enjoyment is supported by Arizpe and Styles (2003) who contend that today's children's stories should incorporate graphical 
representations and illustrations, which contribute in creating meaning in the text since children cherish a mixture of texts and images. A clear distinction between a 'storybook' and a 'picture book' can be drawn far back from Shulevitz (1985, p.19) in his "Writing with Pictures", who distinguishes them as follows:

"Picture books are written with pictures as much as they are written with words. A picture book is read to the very young child who doesn't know how to read yet; consequently, the child sees the pictures and hears the words directly, without having to deal with the intermediate step of reading the printed word. By telling a story visually, instead of through verbal description, a picture book becomes a dramatic experience: immediate, vivid, moving. A picture book is closer to theater and film, silent films in particular, than to other types of books, it is a unique type of book."

\section{Translating oral tales from African languages}

While translation is defined differently by different scholars (Venuti, 1995; Tianmin, 2000; Ordudari, 2008; Webster, 2017), the translation activity tends to lead to the same understanding. For example, Venuti (1995, p.17) describes translation as "a process by which the chain of signifiers that constitutes the source-language text is replaced by a chain of signifiers in the target language which the translator provides on the strength of an interpretation." In the same vein, Webster (2017) defines translation as a "rendering (of a message) from one language into another, and, the product of such a rendition". These two descriptions view translation as a process that transfers a meaningful message from one language to another.

\section{The process of translating folktales and oral tales from African languages}

The translation of folktales and oral tales that are explored in this paper tend to go beyond the language to embrace Ordudari's (2008) perspective of cross-linguistic and cross-cultural communication which ordinarily aims at producing a target language text that is functionally equivalent to a source language text. Such translation also reflects Hatim and Mason (1997), Tianmin (2000) and Ordudari's (2008) view on translation as a simultaneous decontextualization and recontextualization of a meaning, which requires creativity and decision making by the translator. That is why Robinson (1997), Douglass (2002) and Ordudari (2008) qualify translation as an intelligent activity that requires creative problem-solving in textual, social, and cultural conditions. To render 
the message from African folktales into the target language adequately, translators have to choose among translation techniques such as calque, borrowing, transposition, modulation, literal translation, equivalence and adaptation; and they have to take into consideration the translation of linguistic, structural and cultural differences, as Venuti $(1995,1998,2000)$ and (Wang, 2014) argue.

\section{Benefits of translating oral tales from African languages}

Translation of stories from an African perspective offers a great number of opportunities and benefits, and this paper views it as a process that enriches languages and cultures, as a booster of literacy in those languages and cultures, as well as a creative activity.

While language is described as a system of communication that consists of sounds, words, and grammar, or the system of communication used by people in a particular country or a specific type of work (Webster, 2017), this paper applies it to Nida's (2017) description as a system of communication used to maintain and convey culture and cultural ties. Hence, as Nida (2017) argues, language represents a culture, and therefore translation cannot deal with language by ignoring the mirrors of its culture; rather, it must use words in a 'culturally acceptable manner'. Culture is a complex aspect; it includes knowledge, belief, art, law, morals, customs and various other abilities and habits that are acquired by members of a given society (Newmark, 1991,1988).

Translation of stories enriches not only languages and cultures but is also a creative activity that boosts literacy in those languages and cultures. Hence, translation is viewed from Bassnett-McGuire's (1980, in Ordudari, 2008) view about good and effective translation, which is a translation that fulfils the same purpose in the new language as the original did. Such translation requires developing a new situation, new design and new system for audibility, from the original audience to the target audience (Ordudari, 2008). However, it offers some challenges.

\section{Challenges of translating oral tales from African languages}

Translating African folktales, oral literature and picture books was reported to be both interesting and challenging. Mutahi (1987) and Okombo (1994) pointed to the 
challenges by indicating that there is something lost when translating this genre from one language to another, and such a loss is prompted by differences in both the structure and the culture between the source language and the target language. $\mathrm{He}$ summarises the loss as follows:

Translation is just like chewing food that is to be fed to the others. If one cannot chew the food oneself one is to be given the food that has been already chewed. Such food however is bound to be poorer in taste and flavor than the original. (Mutahi, 1987, p.133)

Similarly, other challenges include the translation of linguistic and cultural differences (Venuti, 1995), linguistic untranslatability (Newmark, 1988), linguistic and cultural domestication and foreignization (Venuti,1998; Venuti, 2000; Wang, 2014), and special characteristics of languages like agglutinating Bantu languages or differences in morphological structure among African languages (Nida, 2017). Foreignization refers to the translation strategy in which the target text keeps something of the foreignness of the original; whereas domestication is a target culture-oriented translation strategy in which unusual expressions to the target culture are transmitted and changed into some familiar ones to make the translated text easy to be used/ understood by the target reader (Wang, 2014). Wang (2014) argues that domestication is a strategy that better passes on the spirit of original works while foreignization may serve in expressing the contents of literary works. In the same spirit, Venuti (1998, p.108) had introduced the concept of "Remainder" as the collective force of linguistic forms that outstrips any individual's control and complicates intended meanings. In this regard, he confirms that translation can lose linguistic and cultural features of the foreign text. Such a loss sometimes leads to what Newmark (1988) describes as "linguistic untranslatability", which refers to failure to find a target language equivalent due to differences between the source language and the target language. Domestication comes as a strategy to solve that challenge because it enables the foreign text to be rendered with values that are specific to the targetlanguage culture (Venuti, 1998). Regarding the challenge of translating linguistic and cultural differences, Venuti $(1998,2000)$ and (Wang, 2014) still argue that the issue about the proper and effective techniques to convey and translate both linguistic and cultural differences elements is still debatable. 
Another translation challenge is based in differences in morphological structure between the original language and the target language, and such differences are often difficult for the translator, as Nida (2017) argues. For example, the translator may come across a language that does not have passive form while the target language has it. This leads to what Nida (2017) describes as special characteristics of languages. Some illustrative examples of such special characteristics of languages can include French Passive voice or French nominalisation versus English passive voice or English verbalisation: à notre dernière rencontre (French nominalisation) = When we last met (English verbalisation).

\section{Specificity in translating African agglutinating Bantu languages}

In addition to the translation challenges mentioned above, African agglutinating Bantu languages have particular specificities, which are challenging in translation. Such African agglutinating Bantu languages include Kinyarwanda and Kiswahili, which combine several words or several morphemes into one word, with the possibility of conveying different meanings in one word (Nida, 2017). The example below serves as an illustrating demonstration, where the same meaning is expressed with different number of words and morphemes in English, French Kinyarwanda and Kiswahili:

a. English: I will teach you = /I/ /will//teach//you /

$$
\begin{array}{lllll}
1 & 2 & 3 & 4 & \text { (4 words in English) }
\end{array}
$$

b. French: Je t'enseignerai $=/ \mathrm{Je} / \mathrm{t}$ '/ /enseignerai/

$$
123 \quad \text { (3 words in French) }
$$

c. Kiswahili: Nitakufundisha $=$ Ni-ta-ku-fundisha

$$
\begin{array}{lllll}
1 & 2 & 3 & 4 & \text { (4 morphemes constituting } 1 \text { word) }
\end{array}
$$

d. Kinyarwanda: Nzakwigisha $=\mathrm{N}-z a-k u-i g i s h a$

$$
\begin{array}{lllll}
1 & 2 & 3 & 4 & \text { (4 morphemes constituting } 1 \text { word) }
\end{array}
$$

The examples a, b, c and d above display differences based on specific characteristics of languages, namely English and French which belong to Indo-European or ProtoIndo-European language family (Bock \& Mheta, 2013; Akmajian, Demers, Farmer and Harnish, 2001); and Kiswahili and Kinyarwanda which belong to African Bantu language family (Books, 2010). As indicated in examples above, English and French 
have many words, but Kinyarwanda and Kiswahili have one word with various morphemes. That is why Kinyarwanda and Kiswahili are categorised in agglutinating Bantu languages, which combine several morphemes in one word (Books, 2010; Bock \& Mheta, 2013; Nida, 2017).

This section on literature review has given a glimpse on translating African folktales, oral tales and picture storybooks, with the benefits, opportunities and challenges in translating them. The next section describes the methodological perspective of the paper.

\section{Research design and data generation strategies}

The paper adopts a qualitative design. As a starting point, a workshop was organized in April 2017 at the University of Rwanda - College of Education (UR-CE), with the purpose of exploring how South African Institute of Distance Education's (Saide) African Storybook Initiative could be used as a platform for reading materials to supplement reading materials for Rwandan children. That is why the target audience for the workshop was early grade primary school teachers, Primary Teaching Training College tutors, teacher educators and pre-service teacher-trainees involved in language teaching (English, Kinyarwanda, French and Kiswahili), and language teaching methodology in Rwandan schools. The data for this paper were generated and collected from this workshop process that started in April 2017.

\section{Sample size and sampling techniques}

Thirty-two educators from different schools in Rwanda participated in the workshop and constituted the sample. They include ten primary school teacher educators, ten tutors from Teacher Training Colleges, seven university lecturers, three pre-service high school teacher-trainees and two trainers from Saide. They were selected using purposive sampling technique, based on their experiences in language and literacy teaching as well as teacher training, focusing on the four languages used in Rwandan schools, namely English, French, Kiswahili and Kinyarwanda. The workshop introduced the participants to the African storybook initiative and familiarised them with the Read and Translation functions on the African Storybook website. The workshop provided them with tips on how to create stories of their own and translate those already on the website. Thereafter, each participant was asked to write a story; they 
discussed the stories in groups of four and chose one story which they agreed to be the best. The selected stories in each group were collected, edited and then uploaded on the African Storybook website. Participants also translated picture storybooks from other languages into Kinyarwanda and published them on the African Storybook website.

\section{Data collection instruments}

The main instruments that were used to collect data for this paper are questionnaires, individual interviews and observations. The researchers followed up and observed the workshop process as trainees. They were therefore participant observers; they asked questions about the activities that were completed by different group members during the workshop. All the participants filled in the questionnaire and ten of them were interviewed. They were interviewed individually, using semi-structured interviews. They filled out the questionnaires and were interviewed about their experiences with translating and creating children stories along the workshop. Observation schedules also supplemented the questionnaires and interview schedules.

\section{Data analysis and interpretation}

To analyse the collected data and interpret the findings, the analysis for qualitative data followed thematic content analysis (Creswell, 2009) where themes and categories were produced from data. In this regard, themes that emerged from the questionnaires, interviews and observations were analysed and interpreted in line with the existing literature on translation and creation of children's picture storybooks. Hence, methodological triangulation, where different measures or research instruments were used to investigate the phenomenon (Mackey \& Gass, 2005) was not only used for data collection but also data analysis.

\section{Informed consent for ethical consideration}

All ethical considerations were adhered to by ensuring confidentiality, voluntary participation and filling consent form and freedom to withdraw from the study at any stage of the research, on the side of participants. The research validity was ensured by the technique of triangulation, especially the methodological triangulation (Mackey \& Gass, 2005), as three different research instruments namely the questionnaires, interviews and observations were used to investigate and cross-check the participants' 
information on their experiences with translating and creating children's picture storybooks.

\section{Research findings}

As the thematic content analysis was used to analyse the data, the findings are presented following the themes and categories of participants' experiences with translation and creation of online stories during the workshop. Salient themes emanated from participants' responses from the questionnaires and interviews, while observations cross-checked the participants' responses from questionnaires and interviews. Having translated some stories from English or French or Kiswahili into Kinyarwanda during the workshop, participants reported on their experiences of translating folktales and oral tales from other languages into Kinyarwanda. They also created Kinyarwanda folktales into picture books and posted them on the African Storybook website. The salient themes and categories from their experiences are the following:

\section{Teachers' experiences with translating storybooks into Kinyarwanda}

In regard with participants' experiences with translating, adapting and creating folktales from other languages into Kinyarwanda, the occurring themes from participants' responses include: (i) Difference in story levels between the original and the translated stories, (ii) Special features of African agglutinating language in determining reading levels, (iii) 'foreignization' of translated stories based on cultural clashes, (iv) Stories specificities in reinforcing critical thinking, and (v) differences in length between the original and the translated stories. These experiences are presented with details and evidence as follows:

\section{Experience 1: Difference in story levels between the original and the translated stories}

The salient experience reported by participants, after translating some folktales from English into Kinyarwanda, is that English story levels are not equivalent to Kinyarwanda translated story levels due to clusters. Their experience with the storybooks on the African storybook Initiative website was guided by the categorisation of reading levels into five different levels, namely level 1, 2, 3, 4 and 5. The factors that are considered to classify a story at a given level include the number 
of words in a sentence, the level of simplicity or complexity and familiarity of vocabulary, sentences and plot, and high-interest topics, as reflected in Collins Children's books (2017). Participants compared the general characteristics of levelled stories between the original English stories, and the Kinyarwanda translated versions. They realised that the nature of the source and target language was somehow different. Therefore, a storybook's level varied from the original language to the translated version, whereby a simple term in one language got a complex equivalent in the translated stories. Participants experienced this while translating African storybook stories from English into Kinyarwanda on the African Storybook platform. As evidence, participants translated English level 1 stories such as "Counting animals" and "Different plays" into Kinyarwanda. The translated titles of the two stories were "Kubara inyamaswa" and "Imikino itandukanye or Imikino inyuranye". The comparison of the titles in the two languages revealed that the Kinyarwanda titles could not be read and understood easily by a level 1 reader due to consonants cluster sounds in these titles. The participating teachers indicated that Kinyarwanda consonant cluster sounds such as 'ny', 'sw', 'mb', 'nd', 'shy' and 'nyw' are too complex and difficult for level 1 readers because these clusters are taught in grades two and three in Rwandan schools, where learners are mostly level two and three readers. However, such complexity is not necessarily the case for English as it can be seen in the following example, drawn from the story "Counting animals":

- Two giraffes are going to drink water (English):

- Udusumbashyamba tubiri tugiye kunywa amazi (Kinyarwanda translation, with highlight on consonant cluster sounds)

The highlighted consonant cluster sounds in the Kinyarwanda translation illustrate how the story changes the reading level when translated from one language to another. Further examples can be drawn from the 'Different plays' story, as described in Table 1 below: 
Table 1: Difference in categorising story levels (reading levels) in English and Kinyarwanda based on cluster sounds

\begin{tabular}{|l|l|l|}
\hline Page & $\begin{array}{l}\text { Words and phrases in } \\
\text { original story in English }\end{array}$ & $\begin{array}{l}\text { Words and phrases in } \\
\text { Kinyarwanda translation }\end{array}$ \\
\hline 1 & Skipping & Gusimbuka \\
\hline 2 & Running & Kwiruka \\
\hline 3 & Jumping & Gusimbuka \\
\hline
\end{tabular}

Source: Stories from: www.africanstorybook.org

The above-mentioned examples are evidence that story levels vary from one language to a translated version in another language. While the English words 'skipping, running and jumping' still keep the story to reading level 1, their equivalents in Kinyarwanda, namely 'Gusimbuka, Kwiruka and Gusimbuka' automatically change and shift the story to reading level 2 or 3 due to the highlighted cluster sounds. That is why the participating teachers suggest that reading levels in Kinyarwanda should be determined according language and educational curriculum, in addition to the aforementioned factors. The participating teachers confirmed that it is not easy to translate a level 1 story from English into Kinyarwanda without considerably changing its content. The reason is that it is unusual to communicate in Kinyarwanda without using consonant clusters. In other words, accuracy of, and faithfulness to, the source language are hard to achieve when the story is being translated into Kinyarwanda.

To overcome the above-mentioned translation challenge, that is to attempt to keep the story at level 1 in the Kinyarwanda translated version, the participating teachers modified the words like 'imbeba' (mouse) into 'akabeba' (small mouse); 'inkoni' (a stick) became 'agakoni' (a small stick), etc, to minimize consonant cluster sounds in Kinyarwanda version for reading level 1. However, they could not find a word for 'injangwe' (cat) which does not contain a consonant cluster sound. Thus, they had to rephrase it as 'agakoko gahiga utubeba' (a small animal which hunts small mice). In a nutshell, translators had to be aware of the order in which letters and consonant clusters are taught to different levels in Rwandan schools, so as to translate and adapt translated stories to different reading grades and then help early grade readers to find enjoyable and friendly stories at their levels of literacy skills. Translating such stories into picture books was the best solution to help children understand and enjoy the 
stories, because, as Arizpe and Styles (2003) argue, today's children's stories should incorporate graphical representations and illustrations to contribute in creating meaning in the text. Such a solution to the translated versions helps children's understanding, despite the changing reading level, as shown in the Kinyarwanda translation above. This benefit was revealed to be one of the effectiveness of Saide's African Storybook Initiative.

In regard with the participating teachers' experiences in turning Kinyarwanda folktales into online English picture books, they reported that the translation process was revealed to be a difficult exercise because Kinyarwanda folktales are traditionally meant to be told or narrated to a live audience (especially children) while the storybooks have to be read (both text and pictures). The translated folktales had to preserve and perpetuate social and cultural values and norms from one generation to the next one, as Miruka and Sunkuli (1990) had argued. Thus, the teachers' experience in translating and adapting Kinyarwanda folktales into English picture stories offered both opportunities and some challenges.

\section{Experience 2: Special features of African agglutinating languages in determining reading levels}

As indicated in Experience 1 above, the participating teachers found it challenging to get Kinyarwanda level 1 stories due to the presence of several cluster sounds. They also reported to have encountered challenges in determining reading levels for Kinyarwanda based on the number of words, due to the nature of Kinyarwanda as one of African agglutinating languages. It is indicated that Kinyarwanda is one of the Bantu languages which are categorized into 'agglutinative or agglutinating languages', which combine several words or several morphemes into one word which, from a semantic perspective, to form a complete sentence or phrase (Akmajian, Demers, Farmer and Harnish, 2001; Books, 2010; Bock and Mheta, 2013; Nida, 2017). The participating teachers provided some illustrating examples in the stories, where the translation of one Kinyarwanda word embedded several words in English:

- "Nzamugukundira" (Kinyarwanda) = I will love him for you (English);

- "Nyamutegerakazazejo" (Kinyarwanda) = A man who plans for the future (English); 
- "Nzamukubwirira" (Kinyarwanda) = I will pass the message to him/her on your behalf (English);

- "Uzabansuhurize" (Kinyarwanda) = Greet them / Say hello to them on my behalf (English);

- "Nyamutegerakazazejo" (Kinyarwanda) = who waits for tomorrow's opportunity (English).

These examples above show the specificities of Kinyarwanda as an African agglutinating language where one word combines several morphemes to make a full sentence, which is made of several words when translated into English. The opportunity for such characteristics of Kinyarwanda language is that different meanings, and moral lessons are conveyed in single words. However, this is very challenging for the reader: while readers in African agglutinating languages like Kinyarwanda have to process the meaning of a single word (made of several morphemes), the readers in other languages, including English, have to process the meanings of different words and how they link up together to form the sentence meaning. Reading proficiency is often determined by the number of words that a child can read per minutes, and this is very challenging if we compare Kinyarwanda with English. Thus, determining reading levels on the basis of the number of words as it is done in English may not necessarily work for Kinyarwanda because 'full sentences made of one single word' are very common in Kinyarwanda and in other African agglutinating languages. That is why this paper suggests that the specificity of each language should to be taken into consideration when counting the number of words for each reading level. The same applies to reading skills evaluation while determining the number of words that readers are expected to be able to read per minute.

\section{Experience 3: Foreignization of translated stories based on cultural clashes and lack of appropriate illustrations}

The participating teachers indicated that Rwandan culture is rich in folktales with both human and animal characters and monsters. They reported having experienced some challenges when they attempted to adapt such stories into picture stories, especially about illustrating monsters and ogres. One example is "Akavumburamashyiga" (a kind of small animal that devours children who are disobedient). They reported that they 
found it difficult for any illustration specialist to imagine what this animal looks like while in a folktale people would describe such animals in a way that will frighten children to keep some ethics and some moral lessons.

They reported that the challenge became bigger when the text was to be read across cultures. For instance, the illustration of a drum (ingoma) in some folktales was to be adapted to three cultural perspectives, namely Rwanda, Uganda and Burundi respectively. Participants indicated that illustration specialists may come up with the following different illustrations, though somehow related:

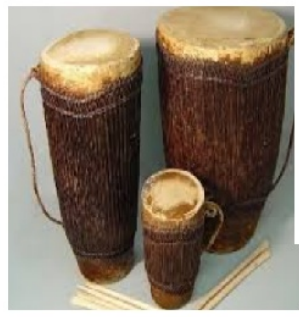

RWANDA

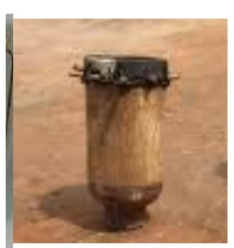

BURUNDI

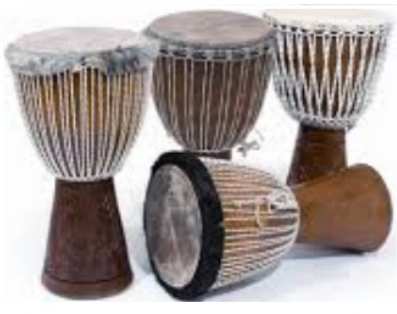

UGANDA

Source: Different types of drums in East Africa, retrieved from https://www.jumia.ug/ uganda-djembe-drum-brown-72878.html on 18 March 2019.

As much as this is likely to be a challenge which may prompt cultural clashes, it also constitutes a window through which children from one cultural background see what other cultures look like. To translate such folktales from different cultural perspectives, the translators have to rely on some translation strategies like linguistic and cultural domestication and foreignization (Venuti,1998; Venuti, 2000; Wang, 2014) and linguistic untranslatability (Newmark, 1988). In this regard, the participating teachers had to keep some foreignness of the original story (foreignization) but at the same time attempt to adapt the unusual concepts to familiar concepts (domestication) in the translated text to make it understood by the target reader, as Wang (2014) explained. Participants experienced both foreignization and domestication; they indicated that Saide's African Storybook Initiative is offering plenty of such experiences, and commended that Saide's picture books facilitate easy understanding and readability by combining texts and images. 


\section{Experience 4: Differences in length between the original and the translated stories}

The participating teachers commented that most of Kinyarwanda folktales tend to be lengthy in nature, due to three aspects. The first aspect is the agglutinating nature, as discussed earlier. They observed that even with the same number of words, most Kinyarwanda words tend to be longer than their English equivalents. For example, the English word "oval" is equivalent to Kinyarwanda word "Umwiburungushure". With such examples, participants commented that the Kinyarwanda language tends to offer more opportunities for older children to practice reading, while it tends to be a challenge for young children to read for a single sitting. Such a challenge may prevent the children from enjoying the stories, and this is likely to be the reason why participants tend to conclude that it is difficult to adapt the stories to the children's reading level in Kinyarwanda, by comparing the number of words for each level, in both English and Kinyarwanda. Hence, participants revealed that they had to delete some parts of the original folktales in Kinyarwanda while translating them into English; as the adaptation required rewriting the story with respect to the general message which embodies the moral lessons to be instilled in children.

The second aspect that make Kinyarwanda folktales lengthy is that they are full of repetitions and details. The participating teachers narrated that the Rwandan folkloric stories are full of repetitions, and repetition was a way of inviting the audience to participate (repeating together) and help the storyteller to recall the story for a long time. Repetition was also done as a way to emphasise very important values and moral lessons. They indicated that the opportunity offered by these repetitions is to ease memorisation and facilitate the mastery of storytelling style. They gave an example of the Kinyarwanda story called "Nyiramuhimbo", which embeds a part consisting of seven lines that are repeated four times throughout the story. Hence, they raised a concern to story converters in other languages that in case the repetitions are omitted, the tale will lose it very important essence and, if the emphasis is to be kept, the challenge is how to do it in online picture stories.

The third aspect for repetitions in the Rwandan traditional folkloric stories was to 'keep time going' as most of these stories were told to children to keep them awake till dinner was ready because they would mostly be feeling sleepy. Hence, the participating 
teachers indicated that the nature of Kinyarwanda folktales is that they provide all the information to the listener so that curiosity is satisfied and that they are not left with questions. The notion of 'Kubara inkuru', which is the equivalent of 'telling a story' implies providing all the details, with lasting effect such as moral lessons, memorisation or keep time going as indicated above. However, the picture books preserve the above-mentioned effect and add the development of children's reading skills. The next experience compared the Kinyarwanda stories and their English versions in promoting critical thinking.

\section{Experience 5: Stories specificities in reinforcing critical thinking}

The participating teachers picked some stories they had translated and posted on Saide's African Storybook website and compared the Kinyarwanda version with the English translation, to weight up the extent to which the two languages promote critical thinking. Table 2 below provides some examples in the two languages:

Table 2: Comparison between Kinyarwanda and English stories in leaving room for critical thinking

To read this table, it is to be explained that participants compared Kinyarwanda stories with different English versions that are found on African Storybook website, for different reading levels. The first column is about the picked a part from Kinyarwanda version; the second column is about the translated English version, based on details from the Kinyarwanda version; while the third column picked any other English version of the same stories, for different reading levels. 


\begin{tabular}{|c|c|c|}
\hline Kinyarwanda version & $\begin{array}{c}\text { Adapted English } \\
\text { version with details }\end{array}$ & $\begin{array}{l}\text { English version leaving } \\
\text { room for critical thinking }\end{array}$ \\
\hline $\begin{array}{l}\text { Ikimara kuvanaho } \\
\text { umupfundikizo, hasohokamo } \\
\text { Nyarubwana ihita iyifata } \\
\text { agakanu irajwigigiriza igaca mo } \\
\text { kabiri } \\
\text { (explaining the kind of death } \\
\text { Hare died) }\end{array}$ & $\begin{array}{l}\text { As soon as he removed } \\
\text { the lid, the fierce dog } \\
\text { came out quickly. He } \\
\text { suffocated Hare and } \\
\text { then cut his neck } \\
\text { angrily. }\end{array}$ & $\begin{array}{l}\text { Out jumped a very angry dog! } \\
\text { And that was the end of Hare. } \\
\text { (encourage the reader to } \\
\text { think from different } \\
\text { perspectives: did the dog } \\
\text { devour Hare or just kill } \\
\text { him? How was he killed in } \\
\text { the first place? Etc.) }\end{array}$ \\
\hline $\begin{array}{l}\text { Ndabaregera Mpyisi, kereka } \\
\text { nimwemera kumpa kuri izo } \\
\text { mbuto. Abana bemera } \\
\text { kugabana na Bakame kugira } \\
\text { ngo atabaregera Mpyisi }\end{array}$ & $\begin{array}{l}\text { I am going to report you } \\
\text { to Hyena; unless you } \\
\text { agree to give me some } \\
\text { fruits. The children } \\
\text { agreed to share with } \\
\text { Hare to avoid being } \\
\text { reported to Hyena }\end{array}$ & $\begin{array}{l}\text { I am going to report you to } \\
\text { Hyena ... Unless you agree to } \\
\text { give me some fruits. The } \\
\text { children agreed to share with } \\
\text { Hare. } \\
\text { (the part highlighted in } \\
\text { English version is not } \\
\text { necessary) }\end{array}$ \\
\hline $\begin{array}{l}\text { Bageze mu rugo nyina } \\
\text { amusobanurira ko }\end{array}$ & $\begin{array}{l}\text { When they got home, } \\
\text { his mother explained to } \\
\text { him that ....... }\end{array}$ & $\begin{array}{l}\text { What do you think his mother } \\
\text { said to him? }\end{array}$ \\
\hline
\end{tabular}

Source: Translated stories from www.africanstorybook.org

As it can be observed in Table 2 above, while Kinyarwanda tends to provide details for each story (in the first column), the English version has the possibility of providing details as the Kinyarwanda version (in the second column) as well as the possibility to leave more room for critical thinking and imagination (in the third column). Hence, the African Storybook website provides various versions of English stories, which are at different reading levels. Participants observed that English language has more flexibility of providing room for critical thinking, while other African languages like Kinyarwanda tend to provide more details. The next section discusses and interprets the findings. 


\section{Discussion and interpretation of the findings}

This paper has revealed that translation, adaptation and creation of online picture stories on Saide's African Storybook website provide a number of reading opportunities for children, in Kinyarwanda, English and many other African languages. The first interpretation of such opportunities is that it increases access to early grade reading materials in both African and Western languages. Hence, this platform is one of the solutions to the issue of insufficient reading materials in Kinyarwanda, as highlighted in various studies (Williams, de Montfort-Nayimfashe, Ntakirutimana and O’Sullivan, 2004; Niyomugabo, 2008; Niyibizi, 2015a; Niyibizi, 2015b, Sibomana, 2015) and other African languages as well. The second interpretation is related to the five experiences that the participants went through during the online translation process, on the African Storybook website. Such a process enabled the research participants to identify a number of opportunities and challenges related to the translation process, based on the nature of languages, the traditional nature of folklore and the new trend of picture stories, as well as the criteria of categorisation of reading levels. The overall feeling about the translation process of children stories is that the process experienced a kind of mismatch between English and African languages, but at the same time expanding the horizons for children reading opportunities.

The implication from this study is that it requires teacher educators, who mainly use these online picture stories with young learners, to be creative, careful and adaptive when creating, translating and adapting stories from English and other languages into Kinyarwanda. One lesson drawn from this study is that translation and adaptation of original traditional Kinyarwanda folktales into picture books require to delete some parts of the folktales and rewrite them with respect of the general message which embodies the moral lessons to be instilled in children. Another lesson is that the specificity of each language, namely Kinyarwanda and English, needs to be taken into consideration when counting the number of words for each reading level. The key argument here is that some models for categorising reading levels based on English, French and other Western languages might not match completely with African languages, as the agglutinating languages have shown in this study. Such a mismatch should be taken into consideration when assessing the reading skills which is often determined by the number of words that readers are expected to be able to read per minute. This study has demonstrated that some African agglutinative languages like Kinyarwanda can have a one-word sentence, which is equivalent to several words in 
English, French or other languages. The key benefit of Saide's African Storybook Initiative is that it offers a full range of children reading experiences and literacy practices in a great number of African languages and Western languages.

\section{Conclusion and recommendations}

To conclude, this paper has identified a number of opportunities and challenges that the participating teachers experienced while translating, adapting or turning oral folktales into Kinyarwanda and English online picture books. While the existing literature counts few studies that explored the educators' experiences with translating African traditional folktales, this study has brought its contribution in filling in this knowledge gap. In this regard, it has highlighted the opportunities and challenges offered by translating or turning Kinyarwanda folktales into English picture books and vice-versa. Literacy in African agglutinating languages, which are under-researched, was explored as well. The implication from this paper is that African teacher educators need to bear in mind that adaptation of African folktales requires care and a high level of ability to maintain the meaning and moral lesson of the original tale and make it enjoyable for children. Having worked with a small number of teacher educators, we recommend Saide and the University of Rwanda - College of Education to take this African Storybook Initiative further, by contacting the Rwandan Ministry of Education and Rwanda Education Board so as to approve these online stories and use them in Rwandan primary schools. Even though the participants' experiences emphasised on challenges encountered while translating oral tales from Kinyarwanda into English picture books, the opportunities offered outweigh the challenges. In this regard, several African countries benefit from African Storybook website because it has stories in more than 100 African languages. Such an opportunity should be seized to instil the culture of reading among early grade learners, which boost literacy and provide solid foundation for quality education in African countries.

\section{Acknowledgement}

We are very grateful to Dr Emmanuel Sibomana from University of Rwanda - College of Education and Wellspring Foundation for Education and Prof. Tony Lelliott from South African Institute of Distance Education (Saide) who proofread and edited this paper. Your inputs have been a great contribution to this paper. 


\section{References}

African Storybook Initiative. Retrieved from www.africanstorybook.org, accessed 22nd April, 2017.

Akmajian, A., Demers R. A, Farmer A. K., and Harnish R. M. 2001. Linguistics: An Introduction to Language and Communication (5th Ed.). Cambridge: MIT Press. Arizpe, E. \& Styles, M. 2003. Children reading pictures: Interpreting visual texts. New York: Routledge/Falmer.

Bassnett-McGuire, S. 1980. Translation studies. London \& New York: Methuen.

Bock, Z. \& Mheta, G. 2013. Language, Society and Communication: An Introduction. Pretoria: Van Schaik Publishers.

Books, L. L. C. 2010. Synthetic Languages: Basque Language, Bantu Languages, Ukrainian Language, Fusional Language, Franco-Provençal Language, Synthetic Language. Paperback: Books LLC, Wiki Series.

Collins, H. 2017. Children's books. New York: Harper Collins Publishers. Different types of drums in East Africa. [Online]. Available from: https://www.google.com/ search?q=rwanda + drum + photos\&tbm=isch\&source=hp\&sa=X\&ved=2ahUKEwi 266 fqozhAhUpTBUIHZKmAQIQsAR6BAgGEAE\&biw=1138\&bih=545\&dpr=1.2 accessed 18 March 2019.

Different types of drums in East Africa. [Online]. Available from:https://www.google. com/search?q=burundi+drums + photos\&tbm=isch\&source=hp\&sa=X\&ved=2ah UKEwiVnrWitozhAhUTuHEKHV4TDUYQsAR6BAgAEAE\&biw=1138\&bih=545 accessed 18 March 2019.

Different types of drums in East Africa. [Online]. Available from: https://www.jumia.ug/ uganda-djembe-drum-brown-72878.html accessed 18 March 2019.

Douglass, R. 2002. Becoming a translator ( $2^{\text {nd }}$ ed.). New York: Routledge

Hatim, B. \& Mason, I. 1997. Translator as communicator. London and New York: Routledge.

Killick, S. \& Boffey, M. 2012. Building Relationships through Storytelling. London: The Fostering Network.

Kress G., \& Van Leeuwen, T. 1996. Reading images: The grammar of visual design. London and New York: Routledge.

Miruka, S. O. \& Sunkuli, L. O. 1990. A Dictionary of Oral Literature. Nairobi: Heinemann Kenya. 
Mutahi, K. 1987. 'Translation Problems in Oral literature. The role of Linguistics in communication for development'. Proceedings of the Linguistics Association for SADC, Universities conference, (pp 131 - 135). Harare: Universities (LASU).

Nandwa, J. \& Bukenya, A. L. 1983. African Oral Literature for Schools. Paperback: Longman.

Nida, E. 2017. Linguistics and ethnology in translation-problems. [Online]. Available from: http://www.tandfonline.com/action/journallnformation?journalCode= rwrd20 accessed 2 June 2018.

Newmark, P. 1988. A Textbook on Translation. New York: Prentice Hall.

Newmark, P. 1991. About Translation: Multilingual Matters. Clevedon: Multilingual Matters Ltd.

Niyibizi, E. 2015a. The Rwandan teachers' and learners' perceived speaking proficiency in both Kinyarwanda and English after 2008-2011 consecutive language-in-education policy shifts. Rwandan Journal of Education, 3 (1): 91116.

Niyibizi E. 2015. Language-in-Education Policy Shifts in an African Country: Colonial Confusion and Prospects for the Future. In: Makalela, L. (ed). New Directions in Language and Literacy Education for Multilingual Classroom in Africa, (pp.91116). Cape Town: CASAS.

Niyomugabo, C. 2008. 'La Glottopolitique du KIE/Rwanda: Contribution à une Sociolinguistique Educative'. PhD thesis. Lome: Université de Lome.

Okombo, O. 1994. Oral literature and translation. Nairobi: Nairobi University Press.

Okpewho, I. 1992. African oral literature. Bloomington: Indiana University Press

Ordudari, M. 2008. 'Good Translation: Art, Craft, or Science?'. Translation Journal.

Translation Theory, 12 (1), no page. [Online]. Available from: http://translationjournal.net /journal/43theory.htm accessed 2 June 2018.

Pedersen, M. 1995. Storytelling and the Art of Teaching. Forum Online, 33 (1), 2-5.

Reiss, K. 1989. Text types, translation types and translation assessment. In: Chesterman, A. (Ed.), Readings in translation theory (pp. 105-115). Helsinki: Oy Finn Lectura Ab.

Robinson, D. 1997. Becoming a translator: an accelerated course. London: Routledge.

Rossiter, M. 2002. Narrative and stories in adult teaching and learning. Columbus, $\mathrm{OH}$ : ERIC Clearinghouse on Adult Career and Vocational Education. 
Shulevitz, U. 1985. Writing with pictures. New York: Watson Guptill.

Sibomana, E. 2015. The Roles of Kinyarwanda and English for High Quality Education: New Directions for the Future. In: Makalela, L. (ed). New Directions in Language and Literacy Education for Multilingual Classroom in Africa, (pp.123152). Cape Town: CASAS.

Tianmin, S. J. 2000. Translation in context. [Online]. Available from: http://accurapid. com/journal/36context.htm, accessed 23 November, 2017.

Venuti, L. 1995. The translator's invisibility: A history of translation. New York: Routledge.

Venuti, L. 1998. The Scandals of Translation: towards an Ethics of Difference. London and NewYork: Routledge.

Venuti, L. 2000. (ed.). Translation Studies Reader. London and New York: Routledge

Wang, F. 2014. An approach to domestication and foreignization from the angle of cultural factors translation. Theory and Practice in Language Studies, 4 (11): 2423-2427.

Webster, M. 2017. Online Merriam-Webster Collegiate Dictionary (10th Ed.). Springfield, MA: Merriam-Webster.

Williams, E., de Montfort-Nayimfashe, L., Ntakirutimana, E., \& O'Sullivan, B. 2004. Proficiency in French, English and Kinyarwanda in the Primary and Secondary Sectors of the Rwandan Education System. Unpublished report commissioned by CfBT Education Trust for the Department for International Development. 